\title{
The prospective role of the primary health care nurse practitioner in the prevention and treatment of type 2 diabetes in youth
}

\author{
Munpreet K. Kainth , Diana Sherifali \\ School of Nursing, McMaster University, Hamilton, Ontario, Canada
}

Received: February 20, 2014

Accepted: December 21, 2014 Online Published: January 26, 2015

DOI: $10.5430 /$ cns.v3n2p75

URL: http://dx.doi.org/10.5430/cns.v3n2p75

\begin{abstract}
Background: This paper examines the literature to explore the multidimensional role of primary health care nurse practitioners (PHC NPs) in type 2 diabetes prevention and management in Canadian youth within the elements of the chronic care model (CCM).

Methods: Searches were conducted in 7 electronic databases and key articles and grey literature were also reviewed. Citations were screened for the following inclusion criteria: written in English; involved children or youth 11 years of age or older; and at risk or diagnosed with type 2 diabetes.

Results: One thousand and one hundred sixty nine citations were found; 1,113 were excluded through title and abstract screening. A total of 56 full text manuscripts were assessed for inclusion criteria, yielding 2 that met the key question. Both studies included assessing participants' lifestyle choices as an outcome. The first study assessed prevalence and remission of obesity; whereas the second study measured participant body mass index (BMI). Both studies reported improvements in lifestyle choices with the involvement of a PHC NP.

Conclusions: PHC NP's greatest value and impact currently lies within the community element of the CCM. Additional research examining the PHC NP's role within the remaining elements of the CCM will demonstrate their impact in targeting type 2 diabetes prevention and management in Canadian youth.
\end{abstract}

Key Words: Child, Adolescent, Type 2 diabetes mellitus, Prevention, Treatment, Nurse practitioner

\section{Introduction}

While in the past type 2 diabetes was viewed as a disease limited to middle-aged and older populations, recent decades have seen an increasing impact of this chronic illness on children's lives. ${ }^{[1,2]}$ Type 2 diabetes in children and youth carries additional challenges such as lifestyle modi- fication within family systems and limited efficacious pharmacotherapy options. ${ }^{[3]}$ Youth may reach adulthood with significantly greater health needs and limited financial resources compared to their healthy adult counterparts. ${ }^{[4,5]}$ Likewise, known diabetes related complications occurring before twenty years of age strikingly increases morbidity

\footnotetext{
* Correspondence: Munpreet K. Kainth, NP-PHC, MScN; Email: kainthmk@mcmaster.ca; Address: School of Nursing, McMaster University, Hamilton, Ontario, Canada.
} 
and mortality rates in youth while raising serious economic implications and numerous challenges to the future of the Canadian health care system. ${ }^{[5,6]}$ Collectively, this evidence highlights the urgent need to examine current primary health care (PHC) strategies that address the prevention and management of type 2 diabetes in youth. Existing prevention and management strategies will now be addressed.

Type 2 diabetes prevention and management programs developed by government and professional organizations are striving to curb the rising incidence of type 2 diabetes in children and youth. ${ }^{[7-9]}$ Obesity is the number one modifiable risk factor that has been targeted for diabetes prevention. ${ }^{[3,10-12]}$ Weight maintenance is best targeted by lifestyle interventions such as diet and exercise, however for longterm sustainability of outcomes in youth, these interventions require intensive counselling and teaching to family units about making healthy choices more easily. ${ }^{[3,13,14]}$ Few studies support pharmacotherapy as an effective youth diabetes prevention strategy, and should only be considered on individual risk basis. ${ }^{[3]}$ The management of type 2 diabetes in children and youth is most effective when lifestyle interventions address family health habits through family-oriented behaviour therapy, coupled with dietary and exercise counselling. ${ }^{[3]}$ The initiation of metformin or insulin in children and youth should be considered if glycemic targets are not achieved within three to six months. ${ }^{[3]}$

Primary health care nurse practitioners (PHC NPs) are well positioned, at the primary care level, to be strong and vital advocates for health promotion and disease prevention across the lifespan. In the Canadian context, a PHC NP is a graduate prepared registered nurse with clinical expertise, who provides a full-range of health services to individuals, families and communities, in partnership with allied health care providers. PHC NPs use advanced expertise and clinical reasoning and provide integrated and accessible services that address health, health promotion, illness and injury prevention, and diagnosis and treatment of illness and injury, while developing and sustaining partnerships with patients. ${ }^{[15,16]}$ To that end, there is evidence to support that the care provided by PHC NPs achieves outcomes that are equivalent to physician care, at a comparative lower cost to the health care system. ${ }^{[17-21]}$ This demand for innovative and collaborative practitioners, such as PHC NPs, to meet the needs of children and youth at risk for or living with type 2 diabetes is increasing.

Currently there is a greater need to focus on chronic illness, with a need to improve the quality of chronic care delivery, ${ }^{[22,23]}$ utilizing the chronic care model $(\mathrm{CCM})$. The refined CCM identifies six essential elements in a health care system necessary for the delivery of high quality effective chronic illness care: 1) health systems, including organization of health care; 2) community, including resources and policies; 3) self-management support; 4) delivery system design; 5) decision support; and 6) clinical information systems (see Figure 1). ${ }^{[24]}$ Research indicates that improvements in chronic illness care are most effective when interventions include multi-pronged strategies, such as those exhibited in the CCM. ${ }^{[24]} \mathrm{A}$ recent review by Coleman, et al. ${ }^{[25]}$ examined articles published since 2000 that assessed the effectiveness of integrated practice changes utilizing CCM elements within a variety of PHC settings and concluded that the CCM was an effective framework in guiding practice redesign for chronic conditions. ${ }^{[25]}$ To that end, it is within the context of the CCM that the literature has suggested that PHC NPs are essential candidates who play a pivotal role within inter-professional teams to successfully address the rising rates of diabetes among Canadian youth. ${ }^{[26]}$ The purpose of this paper is to systematically review the literature for evidence of the PHC NP role in type 2 diabetes prevention and management in youth. Interventions addressing the prevention and treatment of type 2 diabetes in youth will be reviewed, appraised and examined within each element of the CCM to demonstrate the potential value and impact of the PHC NP in this regard.

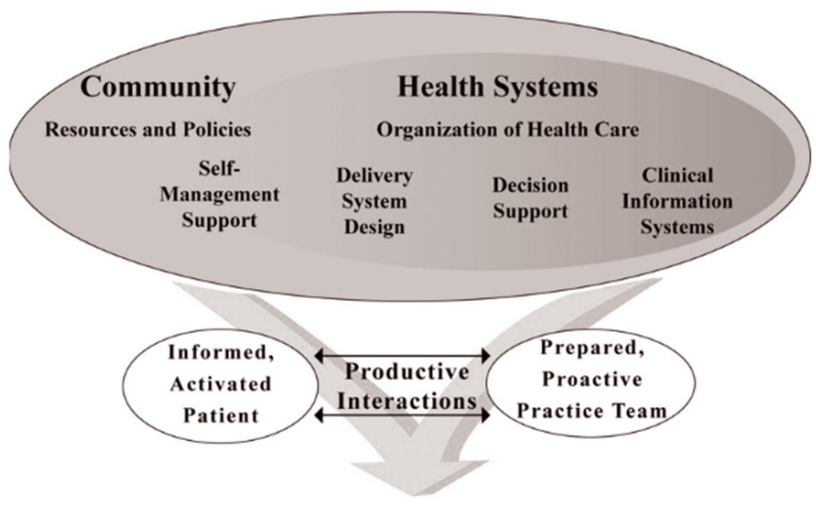

Improved Outcomes

Figure 1: The expanded chronic care model

The "health system" element encompasses care coordination across organizations to reach defined improvement goals, thereby encouraging comprehensive system change to create and sustain a culture that promotes safe, high quality care. ${ }^{[24,33]}$ "Delivery system design" refers to the way in which health practices are organized and conducted. Improvements in chronic illness care requires re-design of current health care delivery systems; shifting from a reactive to a proactive approach. "Decision supports" require a prepared practice team to provide up-to-date evidenceinformed chronic illness care. Examples of decision supports include the regular use of evidence-based practice guidelines, ongoing provider education and access to specialist expertise. ${ }^{[24,33]}$ Furthermore, relevant and timely data about individuals, populations and their health outcomes is provided by "clinical information systems". These facilitate information sharing between providers to coordinate care, improve health care decisions, allow perfor- 
mance monitoring, and evaluate quality improvement efforts. ${ }^{[22,24,33] ~ " S e l f-m a n a g e m e n t ~ s u p p o r t " ~ i s ~ a n ~ e l e m e n t ~ o f ~}$ the model which emphasizes the patient's role in managing their health. Effective self-management support relies on a collaborative process between patients and providers in care planning, empowering patients and families to cope with chronic illness. "Community" is an element that encompasses resources and policies, such as effective community programs and development of partnerships that support and expand a health system's care for the chronically ill.

\section{Methods}

The Prisma Method was utilized to direct this systematic review. ${ }^{[27]}$ Relevant literature from 1990 to August 2013 was searched pertaining to type 2 diabetes prevention and treatment in youth. Specifically search terms such as "child", "youth", "adolescent”, "type 2 diabetes mellitus", "prevention", "treatment", "nurse", and "nurse practitioner" were combined and used in the following databases: National Guideline Clearinghouse, health-evidence.ca, DARE, the COCHRANE Library, MEDLINE, PubMed, and CINAHL.
Reference lists of key articles were also reviewed. A search through grey literature was completed to find relevant articles, as outlined in Table 1. Hand searching through the reference lists of government and professional organizations' websites provided additional research pertinent to the research purpose and target population. Finally, experts in pediatric diabetes prevention and management, as well as a PHC NP were also contacted via email or telephone for additional resources.

Eligible studies were in English and included children or youth 11 years or older at risk or being treated for type 2 diabetes. Study designs for effectiveness of nurse practitioners in the prevention and management of type 2 diabetes included randomized controlled trials, systematic reviews, meta-analyses and observational studies. Titles and abstracts were reviewed for relevance and only full text included in the review were assessed for quality. Database reviews were done independently but were reviewed and discussed with an experienced researcher in systematic reviews. A critical appraisal of each included full text literature was completed, using an evidence-based appraisal tool. ${ }^{[28]}$

Table 1: Description of search strategy including data searches and terms

\begin{tabular}{|c|c|c|c|c|}
\hline $\begin{array}{l}\text { Electronic Database and } \\
\text { Journal Archives }\end{array}$ & Grey Literature & Hand Searching & Experts & Search Terms \\
\hline Databases: & MOHLTC $^{\#}$ & A hand search & Pediatric diabetes nurse: Alanna Landry & Child \\
\hline National guideline clearinghouse & PHAC $^{*}$ & through reference & Pediatrician: Dr. Deepa Grewal & Children \\
\hline health-evidence.ca & CNA & lists of articles & PHC NP: Linda Johnson Clatworthy & Adolescent \\
\hline DARE & Health Canada & retrieved as well & & Diabetes mellitus, Type 2 \\
\hline Ovid medicine & Statistics Canada & publications has & & Risk \\
\hline PubMed & $\begin{array}{l}\text { Center for disease control \& } \\
\text { prevention }\end{array}$ & been conducted & & Canada \\
\hline CINAHL & World health organization & & & Epidemic \\
\hline Journals: & & & & Screening \\
\hline Canadian medical & & & & Prevention \\
\hline association journal & & & & Nurse \\
\hline Canadian journal of diabetes & & & & Nurse Practitioner \\
\hline \multirow[t]{5}{*}{ Pediatrics } & & & & Primary care \\
\hline & & & & Primary Prevention \\
\hline & & & & Community \\
\hline & & & & Multidisciplinary care team \\
\hline & & & & Public policy \\
\hline
\end{tabular}

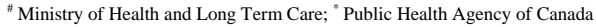

\section{Results}

\subsection{Study search}

Our search located 1,169 potentially relevant citations (see Figure 2). ${ }^{[27]}$ Of these, title and abstract screening excluded 1,113; 56 papers were retrieved and assessed on inclusion criteria. Two studies met the criteria for the key question; both studies were relevant to the community element of the $\mathrm{CCM} ;{ }^{[29,30]}$ and no studies were located that fit our criteria for this review for the health systems, self-management support, decision support, clinical information systems and delivery system design elements. 


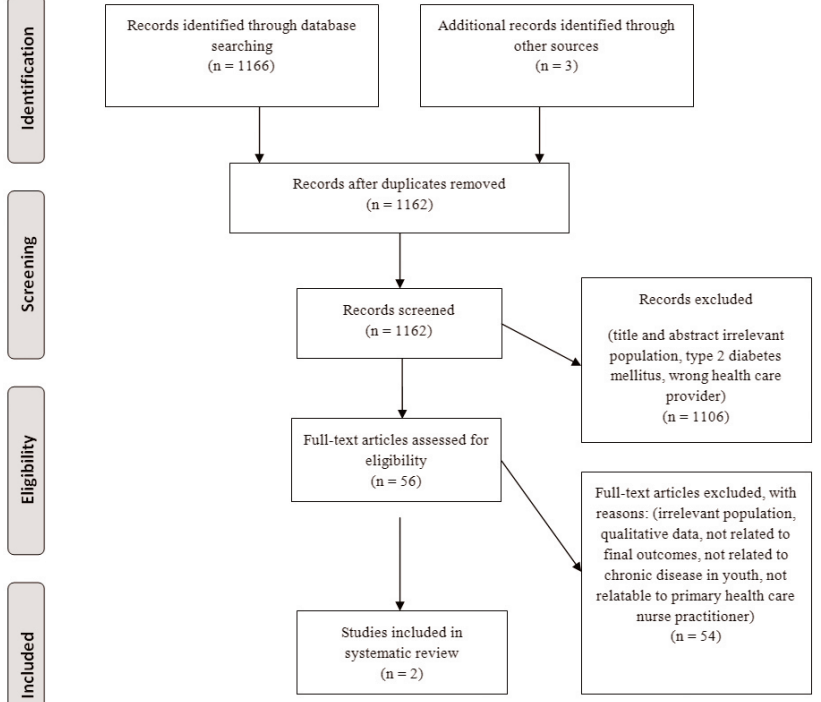

Figure 2: PRISMA flow diagram of search strategy for systematic review. ${ }^{[27]}$

\subsection{PHC NP role in prevention and management of type 2 diabetes in youth}

Of the studies searched in this category, two were found relevant to the community element. Of the two, one was moderate quality research ${ }^{[29]}$ and the other, a pilot study, was of weaker methodological quality ${ }^{[30]}$ (see Table 2). The first study randomized ten public schools in the United States to receive a school-based, interdisciplinary health behaviour intervention, including access to a community-based nurse practitioner, to reduce obesity rates among boys and girls in grades six to eight. ${ }^{[29]}$ Students were randomized to participate in a school-based interdisciplinary intervention in which lifestyle education was integrated into existing curricula using teachers of 4 main subjects, as well as physical education. Education targeted reduction of screen time, intake of high-fat foods, increasing nutrient-rich food intake and vigorous physical activity. The study included 1,295 participants that were assessed at baseline and after two years for: 1) prevalence of obesity, 2) remission of obesity, and 3) changes in lifestyle (i.e. television viewing time, physical activity and fruit/vegetable intake). This study accounted for different patterns of incremental growth in weight and height relative to skinfold velocities and maturational tempo between boys and girls through regression estimates. Ethnic categories, intervention status indicators for randomization pairs and known baseline predictors of obesity (obesity, age, ethnic category, triceps skinfolds and body mass index $[\mathrm{BMI}])$ were controlled for. The following theoretically relevant variables were also tested to distinguish if any other variables were of significance to regression equations: menarcheal status, cigarette smoking, dietary total energy intake per day, percentage of total energy from total and saturated fat, Television and Video Measure score, hours of daily moderate and vigorous physical activity, weight-loss behaviors, and behavioral intentions to walk more, exercise more, or watch less television. For girls, exercising to lose weight was the only variable that significantly contributed to the equation. There were no variables that contributed to male regression models. Although the overall participation rate for both groups was $65 \%$, the intervention schools experienced a decrease in obesity prevalence (Odds ratio [OR] $0.47 ; p=.03$ ); however, this effect was seen primarily in girls and not in boys. Remission was also greater in girls attending schools allocated to the intervention (OR 2.16; $p$ $=.04$ ). Finally, the intervention schools reduced total television viewing time over control schools by 0.40 hours/day ( $p$ $=.003)$, and demonstrated a difference in physical activity $(p=.16)$ or dietary intake $(p=.31)$ compared to control. ${ }^{[29]}$

The second study by Grey, et al. ${ }^{[30]}$ was a pilot study to determine the feasibility of a year-long educational and behavioural intervention in middle schools in Connecticut, United States. A total of 41 students were randomized to the intervention included nutritional counselling, physical activity programming, coping skills training and weekly telephone support, of which was provided by an advanced practice nurse/nurse practitioner. The nutritional counselling utilized a family-centered culturally sensitive interactive approach in counselling youth and families on nutritious options and correct portion sizes to slow weight gain and improve glucose metabolism. The physical activity program occurred after school to encourage youth to engage in numerous kinds of physical activities twice per week, and partner with parents at home an additional three days per week to decrease sedentary behaviors. CST occurs in nutrition classes and focused on teaching youth to learn skills and application to decrease irrational thoughts related to weight. Lastly, the telephone support component of the intervention used an advanced practice nurse/nurse practitioner to telephone youth on a weekly basis to reinforce nutrition and exercise goals and provide CST. Researchers did not state whether a regression analysis was done, or if extraneous variables were controlled, therefore as the authors we cannot presume these controls. Outcome measures included BMI, and lifestyle choices (i.e. dietary patterns, physical activity). At twelve months, there were drops outs for metabolic significant $(n=9)$ and therefore difficult to draw conclusion of efficacy. However, notably, at 12 months the intervention group did improve parental health responsibility ( $p$ $=.03)$, healthier nutrition choices $(p=.05)$ and improved stress management skills $(p=.05)$. The authors concluded that school-based programs tailored to supporting youth at risk for type 2 diabetes do appear to be effective in modifying behaviour of parents and youth. ${ }^{[30]}$

\subsection{Interpretation}

The role of the PHC NP within the "community" element of the CCM is realized through participation in commu- 
nity program delivery, evidenced to have positive health outcomes in youth populations. ${ }^{[29,30]}$ Type 2 diabetes and obesity prevention are closely intertwined, therefore the successful results of a school-based health behaviour intervention in reducing obesity serves as a promising example of how the multifaceted skills of a PHC NP, in collaboration with a multidisciplinary team can optimize health and behavioral change outcomes of youth that are obese or at risk for diabetes.

Table 2: Characteristics, critical appraisal and results of selected studies

\begin{tabular}{|c|c|c|c|c|c|c|c|c|c|c|}
\hline & Country & $\mathbf{N}$ & Setting & Intervention & $\begin{array}{l}\text { Random- } \\
\text { ization }\end{array}$ & $\begin{array}{l}\text { Randomization } \\
\text { concealment }\end{array}$ & $\begin{array}{l}\text { Known group } \\
\text { allocation }\end{array}$ & $\begin{array}{l}\text { Control \& } \\
\text { intervention } \\
\text { groups } \\
\text { similar at } \\
\text { baseline }\end{array}$ & $\begin{array}{l}\text { Follow up } \\
\text { complete }\end{array}$ & Results \\
\hline $\begin{array}{l}\text { Gortmaker } \\
\text { (1999) }\end{array}$ & USA & 1,295 & School & $\begin{array}{l}\text { Behavioural } \\
\text { intervention } \\
\text { including an } \\
\text { interdisciplinary } \\
\text { team including a } \\
\text { nurse practitioner }\end{array}$ & Yes & Unknown & Yes & Yes & Yes & $\begin{array}{l}\text { Obesity rates } \\
\text { decreased in } \\
\text { girls with no } \\
\text { difference in } \\
\text { boys with } \\
\text { intervention } \\
\text { group }\end{array}$ \\
\hline $\begin{array}{l}\text { Grey } \\
(2004)\end{array}$ & USA & 41 & School & $\begin{array}{l}\text { Behavioural \& } \\
\text { educational } \\
\text { intervention } \\
\text { including } \\
\text { telephone support } \\
\text { from an advanced } \\
\text { practicing } \\
\text { nurse/nurse } \\
\text { practitioner }\end{array}$ & Yes & Unknown & Yes & Yes & No & $\begin{array}{l}\text { Intervention } \\
\text { group } \\
\text { improved } \\
{\mathrm{A} 1 \mathrm{C}^{*} \&}^{\text {\& }} \\
\text { dietary } \\
\text { knowledge }\end{array}$ \\
\hline
\end{tabular}

"glycated hemoglobin

The validity of this thorough systematic review is strengthened by the seven databases searched, beginning with evidence-based clinical practice guidelines, and proceeding with the hierarchy of evidence to non-appraised electronic databases. Utilization of Prisma methodology to guide the search process further enhances validity by utilizing consistent inclusion criteria for screening of records.

Screening was limited to English-only literature for pragmatic reasons, as there was no access to translation services. It is postulated that the few non-English studies that may have been eligible for inclusion may not have added any greater value to the elements of the CCM where most literature was found, therefore few studies were likely excluded on this account.

\section{Conclusion}

Type 2 diabetes in youth requires urgent and intensive intervention now. As focus on chronic care gains momentum, it will likely become a permanent feature of the health system landscape, requiring a shift from a reactive to a proactive approach. It remains unclear who will lead and exe-

\section{Discussion}

This rigorous systematic review yielded valuable findings supporting the role of the PHC NP in targeting youth with type 2 diabetes, in the context of the chronic care model. The evidence proposes that the PHC NP's greatest value and impact currently lies within the community element of the CCM. Further research is crucial to validate the role in self-management support, delivery system design, decision support, clinical information systems and health system elements. 


\section{References}

[1] Fagot-Campagna A., Pettitt D. J., Engelgau M. M., Burrows N. R., Geiss L. S., Valdez R., et al. Type 2 diabetes among North American children and adolescents: an epidemiological review and a public health perspective. The Journal of Pediatrics. 2007; 136(5): 664672. http://dx.doi.org/10.1067/mpd.2000.105141

[2] Public Health Agency of Canada. Diabetes in Canada: Facts and figures from a public health perspective. [Internet]. 2011. Available from: http://www.phac-aspc.gc.ca/cd-mc/publications /diabetes-diabete/facts-figures-faitschiffres-201 1/highlights-saillants-eng.php\#chp1

[3] Canadian Diabetes Association Clinical Practice Guidelines Expert Committee. Canadian Diabetes Association 2013 Clinical Practice Guidelines for the Prevention and Management of Diabetes in Canada. Canadian Journal of Diabetes. 2013; 37 (1): S1-S212. PMid:24070926.

[4] Alberti G., Zimmet P., Shaw J., Bloomgarden Z., Kaufman F., Silink M. Type 2 diabetes in the young: The evolving epidemic. Diabetes Care. 2004; 27(7): 1798-1811. PMid:15220270. http: //dx.doi.org/10.2337/diacare.27.7.1798

[5] Pinhas-Hamiel O., Zeitler P. Acute and chronic complications of type 2 diabetes in children and adolescents. The Lancet. 2007; 368: 1823-1831. http://dx.doi.org/10.1016/S0140-6736(07)6 0821-6

[6] Doucet G., Beatty M. The cost of diabetes in Canada: The economic tsunami. [Internet]. 2010. Available from: http: //www.diabetes.ca.libaccess.lib.mcmaster.ca/docume nts/for-professionals/CJD--March_2010-Beatty.pdf

[7] World Health Organization. Diabetes programme. [Internet]. 2012. Available from: http://www.who.int/diabetes/action_on line/en/

[8] Public Health Agency of Canada. Canadian diabetes strategy. [Internet]. 2012. Available from: http://www.phac-aspc.gc.c a/cd-mc/diabetes-diabete/strategy_funding-strateg ie_financeeng.php?phac_source=Diabeteshomepage\&amp ;medium=featurebox\&amp; campaign=Diabetes_feature

[9] Ministry of Health and Long Term Care. Stand up to diabetes. [Internet]. 2009. Available from: http://www.health.gov.on.ca /en/ms/diabetes/en/testing_qa.html\#2

[10] Flynn M. A., McNeil D. A., Maloff B., Mutasingwa D., Wu M., Ford C., et al. Reducing obesity and related chronic disease risk in children and youth: A synthesis of evidence with 'best practice recommendations. Obesity Reviews. 2006; 7(7): 7-66. PMid:16371076. http://dx.doi.org/10.1111/j.1467-789x.2006.00242.x

[11] World Health Organization. 10 facts about diabetes. [Internet]. 2011. Available from: http://www.who.int/features/factfiles /diabetes/facts/en/index $1 . \mathrm{html}$

[12] Jepson R., Harris F., Platt S., Tannahill C. The effectiveness of interventions to change six health behaviours: A review of reviews. BMC Public Health. 2010; 10(1): 538. PMid:20825660. http://dx.doi.org/10.1186/1471-2458-10-538

[13] Kaufman F. R., Shaw J. Type 2 diabetes in youth: rates, antecedents, treatment, problems and prevention. Pediatric Diabetes. 2007; 8(9): 4-6. PMid:17991127. http://dx.doi.org/10.1111/j.1399-5 $448.2007 .00327 . \mathrm{x}$

[14] Summerbell C. D, Waters E., Edmunds L. D., Kelly S. A. M., Brown T., Campbell K. J. Interventions for preventing obesity in children. Cochrane Database of Systematic Reviews. 2005; 3: 1-70. http://dx.doi.org/10.1002/14651858.CD001871.pub2

[15] Anderson A. N. The primary care nurse practitioner. In A. B. Hamric, J. A. Spross \& C. M. Hanson (Eds.) Advanced practice nursing. An integrative approach. St. Louis, Missouri: Elsevier Saunders; 2009. 380-402 p.

[16] Health Canada. About primary health care. [Internet]. 2006. Available from: http://www.hc-sc.gc.ca/hcs-sss/prim/abou t-apropos-eng.php

[17] Brown S. A., Grimes D. E. A meta-analysis of nurse practitioners and nurse midwives in primary care. Nursing Research. 1995; 44(6):
332-339. PMid:7501486. http://dx.doi.org/10.1097/00006 199-199511000-00003

[18] Horrocks S., Anderson E., Salisbury C. Systematic review of whether nurse practitioners working in primary care can provide equivalent care to doctors. British Medical Journal. 2002; 324(7341): 819-823. http://dx.doi.org/10.1136/bmj. 324 .7341 .819

[19] Lenz E., Mundinger M., Kane R., Hopkins S., Lin S. Primary care outcomes in patients treated by nurse practitioners or physicians: Two year follow-up. Medical Care Research and Review. 2004; 61(3): 332-351. http://dx.doi.org/10.1177/1077558 704266821

[20] Dierick-van Daele A.T., Metsemakers J.F., Derckx E.W., Spreeuwenberg C., Vrijhoef H.J. Economic evaluation of nurse practitioners versus GPs in treating common conditions. British Journal of General Practice. 2010; 60(570): e28-35. PMid:20040165. http://dx.doi.org/10.3399/bjgp10X4820 77

[21] Hollinghurst S., Horrocks S., Anderson E., Salisbury C. Comparing the cost of nurse practitioners and GPs in primary care: Modelling economic data from randomized trials. British Journal of General Practice. 2006; 56(528): 530-534. PMid:16834880.

[22] Wagner E. H., Davis C., Schaefer J., Von Korff M., Austin B. A survey of leading chronic disease management programs: Are they consistent with the literature? Managed Care Quarterly. 1999; 7(3): 56-66. PMid:10620960.

[23] Wagner E. H., Austin B. T., Davis C., Hindmarsh M., Schaefer J., Bonomi A. Improving chronic illness care: Translating evidence into action. Health Affairs. 2001; 20(6): 64-78. http://dx.doi .org/10.1377/hlthaff. 20.6.64

[24] Improving Chronic Illness Care. The chronic care model. [Internet]. 2012. Available from: http://www.improvingchroniccare.o

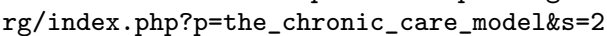

[25] Coleman K., Austin B. T., Brach C., Wagner E. H. Evidence on the chronic care model in the new millennium. Health Affairs. 2009; 28(1): 75-85. PMid:19124857. http://dx.doi.org/10.1377/h lthaff.28.1.75

[26] Lenz E., Mundinger M., Hopkins S., Lin S., Smolowitz J. Diabetes care processes and outcomes in patients treated by nurse practitioners or physicians. The Diabetes Educator. 2002; 28(4): 590-598. http://dx.doi.org/10.1177/014572170202800413

[27] Moher D, Liberati A, Tetzlaff J, Altman DG, The PRISMA Group. Preferred Reporting Items for Systematic Reviews and Meta-Analyses: The PRISMA Statement. PLoS Med. 2009; 6(6): e1000097.

[28] DiCenso A., Guyatt G., Ciliska D. Evidence-based nursing: A guide to clinical practice. St. Louis, MO: Elsevier Mosby; 2009.

[29] Gortmaker S. L., Peterson K., Wiecha J., Sobol A. M., Dixit S., Fox M. K., et al. Reducing obesity via a school-based interdisciplinary intervention among youth. Archives of Pediatrics and Adolescent Medicine. 1999; 153(4): 409-418. PMid:10201726. http: //dx.doi.org/10.1001/archpedi.153.4.409

[30] Grey M., Berry D., Davidson M., Galasso P., Gustafson E., Melkus G. Preliminary testing of a program to prevent type 2 diabetes among high-risk youth. Journal of School Health. 2004; 74(1): 1015. PMid:15022370. http://dx.doi.org/10.1111/j.1746-1 561.2004.tb06595.x

[31] Mechanic R. Will care management improve the value of U.S. health care? Waltham MA: The Health Industry Forum. [Internet]. 2004. Available from: http://healthforum.brandeis.edu/r esearch/pdfs/CareManagementPrincetonConference.pdf

[32] Canadian Nurses Association. Canadian nurse practitioner core competency framework. Ottawa, ON: Canadian Nurses Association. [Internet]. 2010. Available from: http://www.cno.org/Global /for/rnec/pdf/CompetencyFramework_en.pdf

[33] Barr V. J., Robinson S., Marin-Link B., Underhill L., Dotts A., Ravensdale D., et al. The expanded chronic care model: An integration of concepts and strategies from population health promotion and the chronic care model. Hospital Quarterly. 2003; 7(1):73-82. PMid: 14674182 . 